\title{
Solvent Effects on Hydrogen Abstraction Reactions from Lactones with Antioxidant Properties
}

\author{
Carolina Aliaga- ${ }^{-}$David R. Stuart-, Alexis Aspée ${ }^{\ddagger}$, and J. C. Scaiano* \\ - Department of Chemistry, University of Ottawa, Ottawa, Canada K1N 6N5 \\ Facultad de Quimica y Biologia, Universidad de Santiago de Chile. Correo 33 Casilla \\ 40, Santiago de Chile.
}

\section{SUPPORTING INFORMATION}

\section{Experimental Section}

Reagents. di-tert-butyl peroxide and all solvents are reagent or HPLC grade from Aldrich and were used as received. Deuterated solvents $99.9 \%$ pure and dry were commercially available. Ciba Irganox ${ }^{\mathrm{TM}} \mathrm{HP}-136$ was a gift from CIBA.

Synthesis of 4-(3-Hydroxy-2-methyl-4-quinolinoyloxy)-2,2,6,6-tetramethylpiperidine -1-oxyl Free Radical (QT) (3). The QT probe was synthesized by a procedure similar to that described by Hassner ${ }^{1}$. Modifications of the procedure are in reference 2.

Product analysis by HPLC. The dimer formation was detected by HPLC analysis in a Jasco chromatograph provided with a CD (UV-visible) 1595 detector. Mobile phase was $100 \%$ acetonitrile. The chromatogram was compared and the dimer signal formation confirmed by a standard of 5,7,5',7'-tetra-tert-butyl-3,3'-bis-(3,4-dimethyl-phenyl)$\mathbf{3 H}, \mathbf{3}^{\prime} \mathbf{H}$ - $\left[3,3^{\prime}\right]$ bibenzofuranyl-2,2'-dione (dimer 6). Synthesis and characterization of 6 was carried out using the procedure reported previously by our laboratory. ${ }^{3}$

\section{H-abstraction by tert-butoxyl radicals.}

Laser Flash Photolysis. The radical derived from HP-136 was generated from the corresponding compound by laser excitation of tert-butyl-peroxide $5 \% \mathrm{v} / \mathrm{v}$ in the different solvents by using a Lumonics EX-530 laser with a Xe-HCl-Ne mixture generating $6 \mathrm{~ns}$ pulses at $308 \mathrm{~nm}(80-100 \mathrm{~mJ} /$ pulse at the source). Transient signals were captured with a digital oscilloscope, which is interfaced to a computer that also controls the experiment. The system was operated with software written in the LabVIEW 5.1 environment from National Instruments. All experiments were carried out using static cells constructed from $7 \times 7 \mathrm{~mm}$ Suprasil quartz tubing. All samples were purged with a slow stream of either nitrogen or argon. Transient kinetic traces were recorded at $350 \mathrm{~nm}$ in different solvents for a range of concentrations among $0.005-0.05 \mathrm{M}$ in order to obtain plots $\mathrm{k}_{\text {expt }} v s$. [HP-136].

A typical plot is shown in Figure 1 and the inset contains a trace recorded at $350 \mathrm{~nm}$ indicating the formation of the HP-136 radical for a solution $40 \mathrm{mM}$ in anisole. 


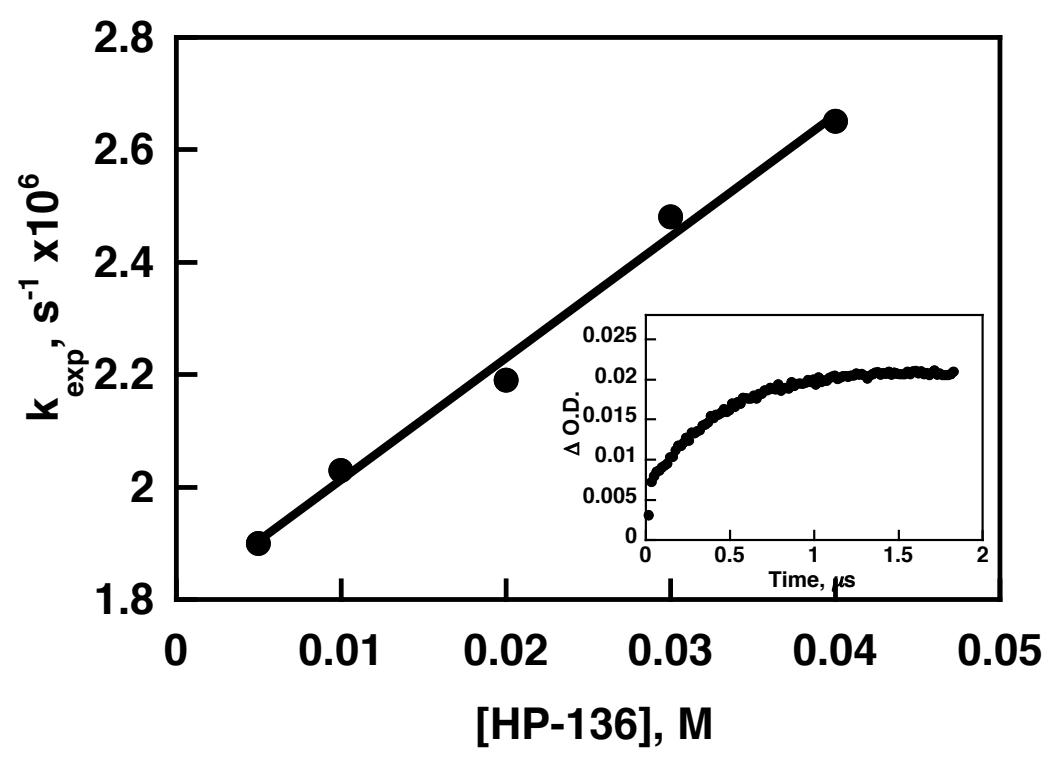

Figure 1. Hydrogen abstraction rate constant is obtained from the slope: $2.2 \times 10^{7} \mathrm{M}^{-1} \mathrm{~s}^{-1}$ in anisole. Inset: trace gave a rate constant $2.5 \times 10^{6} \mathrm{~s}^{-1}$ for a $40 \mathrm{mM} \mathrm{HP}-136$ solution in anisole.

\section{H-abstraction by pre-fluorescent nitroxyl radical probes.}

Fluorescence. A typical profile of fluorescence increase evaluated at $430 \mathrm{~nm}\left(\lambda_{\text {exc }} 360\right.$ $\mathrm{nm}$ ) in methanol and kinetic adjusted to pseudo first order (inset) are shown in Figure 2. Experimental conditions were $10 \mu \mathrm{M}$ QT and $10 \mathrm{mM}$ of HP-136, $25 \pm 1{ }^{\circ} \mathrm{C}$ for the list of solvents employed.

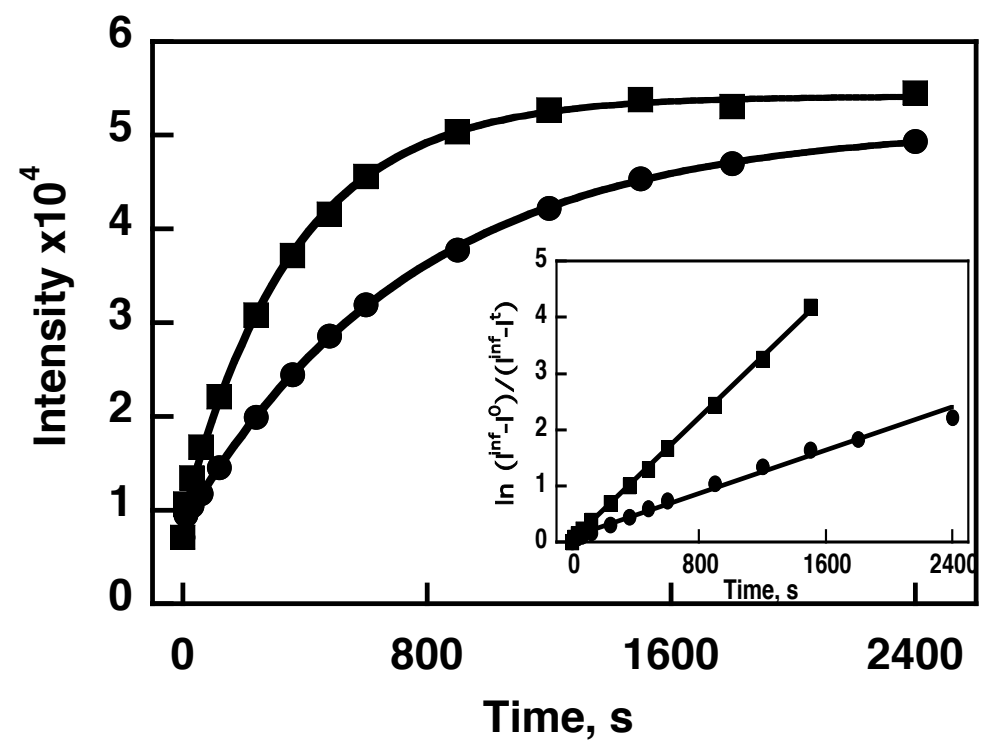

Figure 2. $10 \mu \mathrm{M}$ QT and (•) $5 \mathrm{mM}$ and (घ) $10 \mathrm{mM}$ of HP-136 in methanol 
Kinetics for deuterium effects. ${ }^{1} \mathrm{H}$ NMR spectra were recorded on Bruker AVANCE500 instrument. The kinetic for the ${ }^{1} \mathrm{H}$ exchange was followed by the signal of proton $\mathrm{H}_{\mathrm{a}}$ (1) at $\delta 4.2 \mathrm{ppm}$ of a solution containing $10 \mathrm{mg}$ of $\mathrm{HP}-136$ in $0.75 \mathrm{~mL} \mathrm{CD} \mathrm{CN}_{3}$ after addition of two different amounts of $\mathrm{D}_{2} \mathrm{O}$ to the solution.

\section{References}

1. Hassner, A.; Alexanian, V. Tetrahedron Lett. 1978, 19, 4475-4478.

2. Aspée, A.; Garcia, O.; Maretti. L.; Sastre. R. and J.C. Scaiano, Macromol. 2003, 36, 3550-3556.

3. Frenette, M.; Aliaga, C. Font-Sanchis, E. and Scaiano, J. C., Org. Lett. 2004, 6, 2579-2582. 